\title{
Clinical and histological features of a group of patients with sporadic non-A, non-B hepatitis
}

\author{
MAY BAMBER, AK MURRAY, IVD WELLER, A MORELLI,* PJ SCHEUER, \\ HC THOMAS, SHEILA SHERLOCK
}

From the Departments of Medicine and Histopathology, Royal Free Hospital, Hampstead, London NW3 $2 Q G$ and the *Istituto Clinica Medica, Policlinco, Montecola, Perugia, Italy

SUMMARY Twelve serologically proven cases of non-A, non-B (NANB) hepatitis have been described. The clinical course was mild in 11 patients. One patient, however, presented in portal systemic encephalopathy and required steroid treatment. Nine of the 12 patients continued to exhibit raised transaminase (AST) activities six or more months after the onset of the acute hepatitis. In these immunoglobulin concentrations were normal and autoantibodies were not present in significant titre. Four patients had evidence of previous hepatitis B infection, suggesting that the route of transmission of NANB might be similar to that of hepatitis B virus. A further four patients gave a history which suggests a possible parenteral mode of transmission. Liver biopsies were carried out both in the acute ( 8 cases) and chronic (6 cases) phases of the disease. Histological findings in liver biopsies covered the whole spectrum of acute and chronic hepatitis and 1 patient had cirrhosis. One notable feature in these biopsies was the presence of fatty changes.

Since the development of sensitive serological tests for the diagnosis of hepatitis A and B infection, it has become apparent that there are other hepatitis viruses which have been termed non-A, non-B (NANB). ${ }^{12}$ Several studies have suggested that there are two such viruses with incubation periods of 10-14 days and 7-13 wk..$^{3-5}$ The antigenic characteristics of these viruses have not been fully elucidated, although some workers have described an antigen/antibody $(\mathrm{Ag} / \mathrm{Ab})$ system in association with the 7-13 wk incubation form of the disease. ${ }^{6}$ ?

The prevalence of NANB agents as a cause of sporadic hepatitis varies from $12-25 \% 8$ a and chronic hepatitis may occur in $23-46 \% 1011$ of infected patients. Thus these viruses would appear to be a significant aetiological factor in chronic liver disease (CLD).

In this study we describe the clinical and histological features of a group of patients with NANB hepatitis to determine whether there are features which distinguish this group from other types of hepatitis.

\section{Patients and methods}

The subjects of this study were 12 patients with acute viral hepatitis (Table 1). Ten had been hospitalised in

Accepted for publication 7 May 1981 the Liver Unit of the Royal Free Hospital with acute hepatitis and two were referred from abroad to the above unit with a diagnosis of a past acute hepatitis. In order to be included in the study the patients had to satisfy the following criteria:

1 History of an acute illness consistent with viral hepatitis, accompanied by a rise of serum AST to greater than 2.5 times normal.

2 No previous known exposure to hepatotoxins or excessive prolonged alcohol consumption ( $>80 \mathrm{~g}$ alcohol per day).

3 No evidence of previous chronic liver disease. All were considered to have had acute NANB hepatitis on the basis that they were negative for hepatitis B surface antigen (HBsAg) and IgM antihepatitis A virus (IgM antiHAV). Intrahepatic hepatitis B virus (HBV) infection in the absence of circulating $\mathrm{HBsAg}$ was considered on the basis of a positive hepatitis $B$ core $(\mathrm{HBcAb})$ but negative hepatitis $B$ surface antibody (HBsAb). ${ }^{12}$ These patients were excluded. Criteria for diagnosis of acute type A hepatitis included the presence of $\operatorname{IgM}$ antiHAV during the first three months of the illness. ${ }^{13}$ Whenever acute phase sera were not available for testing and chronic phase or convalescent sera were positive for IgG antiHAV, it was concluded that the aetiological agent was either A or NANB. These patients were also excluded. The diagnosis of acute NANB hepatitis was made if acute phase sera were 
Table 1 Clinical and serological data in NANB patients

\begin{tabular}{|c|c|c|c|c|c|c|c|c|c|c|}
\hline \multirow[t]{2}{*}{ Patient } & \multirow[t]{2}{*}{ Age } & \multirow[t]{2}{*}{ Sex } & \multirow[t]{2}{*}{ Nationality } & \multirow[t]{2}{*}{ Travel abroad } & \multicolumn{2}{|c|}{$H A V$ serology } & \multicolumn{2}{|c|}{$H B V$ serology } & \multirow[b]{2}{*}{$H B c A b$} & \multirow{2}{*}{$\begin{array}{l}\text { History of transfusion } \\
\text { Drug abuse } D \\
\text { Surgery } \quad S\end{array}$} \\
\hline & & & & & $\operatorname{Ig} M$ & $\lg G$ & $H B s A g$ & $H B s A b$ & & \\
\hline 1 & 63 & $\mathbf{M}$ & Saudi Arabian & Middle Fast & - & $\therefore$ & - & & & \\
\hline 2 & 37 & $F$ & British & Major:a & - & & - & $\cdots$ & & $\xi$ \\
\hline 3 & 24 & $\mathbf{M}$ & British & $\ldots$ & - & - & - & & & \\
\hline 4 & 34 & $M$ & British & Europe & - & - & - & $\ldots$ & - & \\
\hline 5 & 33 & $\mathrm{~F}$ & British & $\cdots$ & - & - & - & - & - & $\cdots$ \\
\hline 6 & 66 & $\mathrm{~F}$ & British & Spain & - & - & - & & & $\cdots$ \\
\hline 7 & 26 & $\mathbf{M}$ & British & $\cdots$ & - & - & - & - & & D. T \\
\hline 8 & 28 & M & British & Africa & - & -. & - & & & - \\
\hline 9 & 37 & $\mathrm{~F}$ & British & Israel & - & & * & & - & \\
\hline 10 & 25 & $\mathbf{M}$ & Mexican & Mexico & - & - & - & - & -- & $\mathrm{T}$ \\
\hline 11 & 37 & $\mathrm{~F}$ & Egyptian & & - & - & - & - & - & $S$ \\
\hline 12 & 38 & $\mathrm{~F}$ & British & -- & - & - & - & - & - & \\
\hline
\end{tabular}

negative for IgM antiHAV or chronic phase sera were negative for IgG antiHAV. Epstein-Barr virus $(\mathrm{EBV})$ and cytomegalovirus (CMV) infection could not be excluded serologically due to insufficient serum. The clinical course, however, was not consistent with that of EBV or CMV infection: none of the patients had a pyrexia, sore throat or lymphadenopathy in the acute period. Furthermore, the high incidence of CLD in these patients would not favour a diagnosis of EBV or CMV infection.

The onset of hepatitis was considered to be when the first rise of serum AST activity was noted. If this persisted for six months after the onset of the acute hepatitis, the patients were considered to have developed chronic hepatitis. Liver biopsies were performed at varying stages of the hepatitis ranging from one to 28 months after the onset. All the biopsies were performed percutaneously with a Meninghini needle. They were obtained from 12 patients.

The specimens were processed by routine methods and paraffin sections stained with haematoxylin and eosin, Gordon and Sweets' reticulin method, Shikata's orcein stain, the periodic acid-Schiff stain after amylase digestion and Perls' method for iron. In the histological evaluation, liver-cell damage, type of necrosis, inflammation, Kupffer cell reaction, pigments, cholestasis, fibrosis, bile duct damage and fatty change were semiquantitatively evaluated and given a score from 0 to +++ . Particular attention was paid to the relation of cellular infiltration and liver-cell damage.

The clinical-histological diagnoses (Table 2) were: acute hepatitis with spotty necrosis, acute hepatitis with bridging necrosis (linking centrilobular and portal areas), acute hepatitis with possible transition to chronic hepatitis, ${ }^{14}$ chronic lobular hepatitis, chronic persistent hepatitis and chronic active hepatitis. The last category was subdivided according to severity and the presence or absence of cirrhosis noted.
Liver function tests and serum $\operatorname{IgM}, G$ and $A$ concentrations were determined by routine methods; serum antimitochondrial (AMA), antinuclear (ANF) and anti-smooth muscle (SMA) antibodies were assayed by standard indirect immunofluoresence on rat stomach, kidney or liver substrates.

IgM antiHAV was measured by a modified HAVAb test. ${ }^{15}$ IgM and IgG antiHAV were differentiated by assaying sera for HAVAb before and after absorption of IgG with staphylococcal protein A.

HBsAg was assayed during the acute phase of the disease by radioimmunoassay ( 10 cases) or haemage glutination ( 2 cases). $\mathrm{HBsAb}$ and $\mathrm{HBcAb}$ were determined by radioimmunoassay.

\section{Results}

Of the 12 patients with NANB hepatitis, six were women. The average age was $37 \mathrm{yr}$ with a range between 24 and $66 \mathrm{yr}$ (Table 1). Five gave a history of having been abroad, three came from overseas and two had had blood transfusions in the six months before the acute hepatitis. One patient was a drug abuser and one had had dental surgery in the previous six months; one woman patient had had a dilatation and curettage ( $D$ and $C$ ) of her uterus in the previous six months. Two patients were tatooed but this had been done several years earlier. One patient developed hepatitis in the first trimester of pregnancy.

All 12 patients were icteric during the phase of acute hepatitis. The maximum serum AST activity during this period was $920 \mathrm{IU} / 1$ with a mean of 249 IU/l. In all patients where follow-up was available, two had recovered at six months and nine still had abnormal serum AST activities. Four patients had evidence of previous HBV infection in the acute phase of the illness; four were positive for antiHBs and antiHBc and one for antiHBs alone (Table 1).

None of the patients demonstrated ANF, SMA or 
Table 2 Histological diagnosis in 16 liver biopsies from 12 patients

\begin{tabular}{|c|c|c|c|c|c|}
\hline \multirow[t]{2}{*}{ Patient no } & \multirow[t]{2}{*}{ Diagnosis } & \multirow{2}{*}{$\begin{array}{l}\text { Months } \\
\text { from } \\
\text { onset }\end{array}$} & \multicolumn{3}{|c|}{ Special histological features } \\
\hline & & & Fat & $\begin{array}{l}\text { Dispropor- } \\
\text { tionate } \\
\text { infiltrate }\end{array}$ & Cholestasis \\
\hline 11 & Acute hepatitis with spotty necrosis & 2 & ++ & 0 & + \\
\hline 3 & Acute hepatitis with spotty necrosis (residual) & 2 & 0 & 0 & $\mathbf{0}$ \\
\hline 8 & Acute hepatitis with spotty necrosis (residual) & 3 & 0 & ++ & + \\
\hline 9 & Acute hepatitis with spotty necrosis (residual) & 2 & + & 0 & 0 \\
\hline 12 & Acute hepatitis with bridging necrosis (BHN) & 1 & 0 & 0 & 0 \\
\hline 1 & Acute hepatitis with possible transition to chronic hepatitis & 2 & + & 0 & 0 \\
\hline 5 & Acute hepatitis with possible transition to chronic hepatitis (and BHN) & 3 & 0 & 0 & + \\
\hline 6 & Acute hepatitis with possible transition to chronic hepatitis (and BHN) & 4 & 0 & 0 & 0 \\
\hline 4 & Chronic lobular hepatitis & 9 & + & 0 & 0 \\
\hline 4 & Chronic lobular hepatitis & 20 & $\dot{t}$ & ++ & 0 \\
\hline 11 & Chronic lobular hepatitis & 6 & + & + & 0 \\
\hline 10 & Chronic persistent hepatitis & 12 & 0 & 0 & 0 \\
\hline 1 & Chronic active hepatitis (minimal) & 16 & + & 0 & 0 \\
\hline 7 & Chronic active hepatitis (moderate severity) & 20 & + & 0 & 0 \\
\hline 5 & Chronic active hepatitis (severe with cirrhosis) & 28 & 0 & 0 & 0 \\
\hline
\end{tabular}

AMA positively in a titre greater than $1 / 10$. Immunoglobulin concentrations in 11 of the patients were normal. One patient had a raised IgG concentration which reverted to normal on later testing.

Eight patients had liver biopsies within six months of the acute hepatitis (Table 2). One showed features of acute hepatitis with spotty necrosis, three late residual acute hepatitis, one acute hepatitis with bridging necrosis, and three acute hepatitis with possible transition to chronic hepatitis.

Of the nine patients with chronic hepatitis, six had liver biopsies at variable times ranging between 6 to 28 months after the acute episode. One of these patients had two liver biopsies, at 9 and 20 months after the acute hepatitis. Two patients had chronic lobular hepatitis, one had chronic persistent hepatitis, one was on the borderline between chronic persistent and chronic active hepatitis, one chronic active hepatitis of moderate severity and one had severe active cirrhosis after acute hepatitis accompanied by portal systemic encephalopathy during early pregnancy. There was no history of blood transfusion in this patient. She required prednisolone for her chronic hepatitis.

In general, the hepatic histology was as described for other types of acute and chronic hepatitis. ${ }^{16}$ However, some features were regarded as unusual and may reflect specific histological patterns of one or other types of NANB hepatitis. Fatty change was common both in acute and chronic liver disease (Figs. 1 and 2). It was usually mild $(+)$ but in one patient with acute hepatitis (patient 11) fat was more abundant $(++)$. A degree of sinusoidal infiltration disproportionate to the extent of liver cell damage was found in one patient with acute hepatitis and two with chronic liver disease (Figs. 3 and 4). Cholestasis was found in three of eight biopsies from patients with acute hepatitis and was occasionally severe. In chronic liver disease cholestasis was absent. Other noteworthy features not listed in the Table included striking ballooning degeneration of liver cells found in two patients (patients 11 and 13). In patient 11 the swollen cells contained multiple nuclei giving an appearance reminiscent of neonatal hepatitis (Fig. 1). Bile duct damage was seen in many biopsies in both acute and chronic hepatitis but was always mild and did not correspond to the florid lesions described elsewhere in hepatitis. ${ }^{17}$ Evidence of damage consisted of slight irregularity of the epithelium of the smallest ducts together with infiltration of the epithelium by acute or chronic inflammatory cells.

\section{Discussion}

We have studied 12 patients, six women and six men, who are considered on serological grounds to have had NANB hepatitis. One of the female patients was pregnant when she developed the acute hepatitis, and she also presented with portal systemic encephalopathy. She later developed the severest chronic liver lesion and was given steroids. This is consistent with a previous report that NANB fulminant hepatitis predominantly occurs in females. ${ }^{18}$ In the remaining patients the even sex distribution contrasts with HBV and lupoid hepatitis, where, in the former, there is a predominance of the disease in males, and in the latter in females. It is notable that seven of our NANB patients gave a history of either living or having travelled abroad. Four were Britons and had not been abroad and one patient was born in Egypt but had lived in Britain for most of her life. Four gave a history which suggested their NANB infection could have been acquired via a parenteral route. A further four patients had evidence of previous HBV infection. This suggests that the route of trans- 


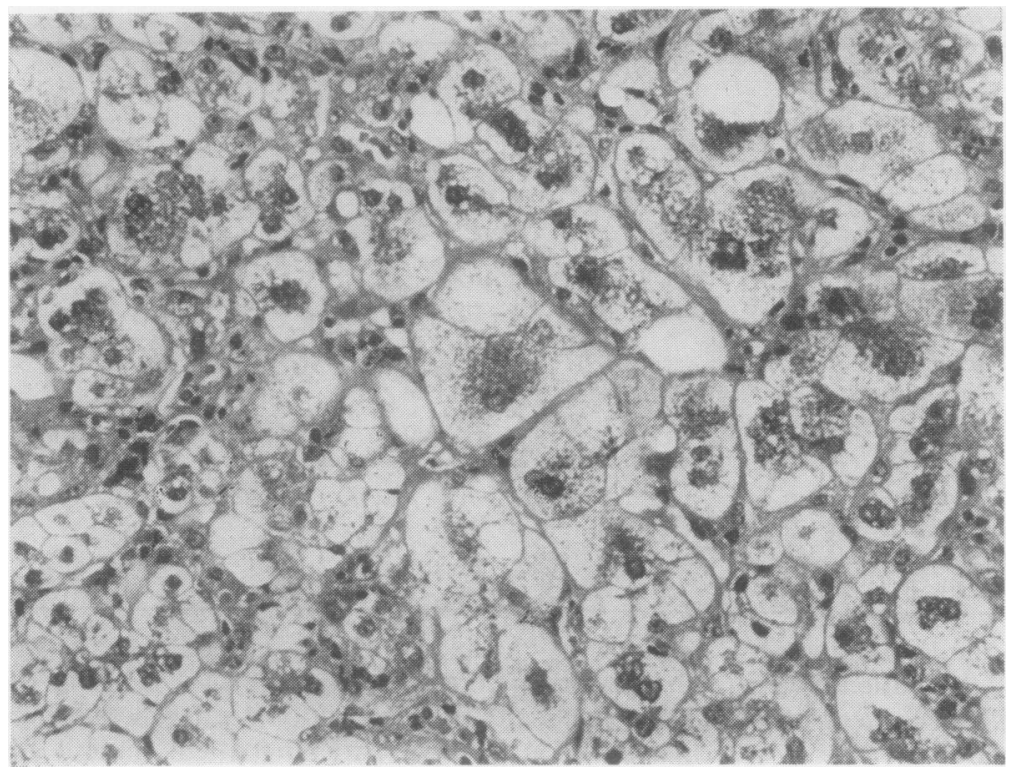

Fig. 1 Case 11: part of liver biopsy five months after onset, showing late acute hepatitis with swollen, multinucleated hepatocytes some of which contain fat vacuoles. Haematoxylin and eosin $x$

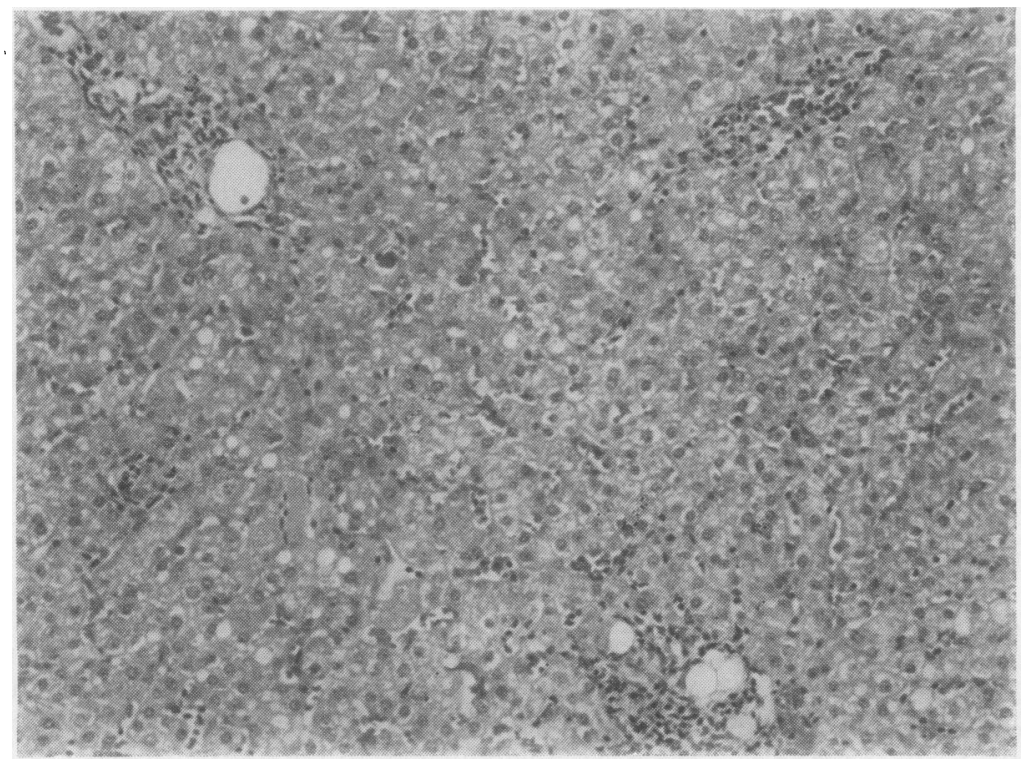

Fig. 2 Case 11: later biopsy, showing chronic active hepatitis. The portal tract is irregularly enlarged and inflamed. Fat vacuoles are seen in the parenchyma. Haematoxylin and eosin $\times 145$.

mission of NANB is similar to that of HBV All these patients with HBV markers had liver biopsies in the acute phase of the illness. None showed features of chronic liver disease. Other workers who have reported chronic liver disease following sporadic NANB hepatitis did not look for antiHBc positivity in the absence of antiHBs as an indication of recent or active HBV infection. ${ }^{19}$ Two patients had to be excluded at the onset of the study because of a positive antiHBc and a negative antiHBs in the acute period.

Nine of the 12 patients still exhibited raised serum AST activities six months after the acute onset. This figure which is higher than other workers have observed $^{1011}$ may be artefactual being related to the selective referral of patients with probable chronic 

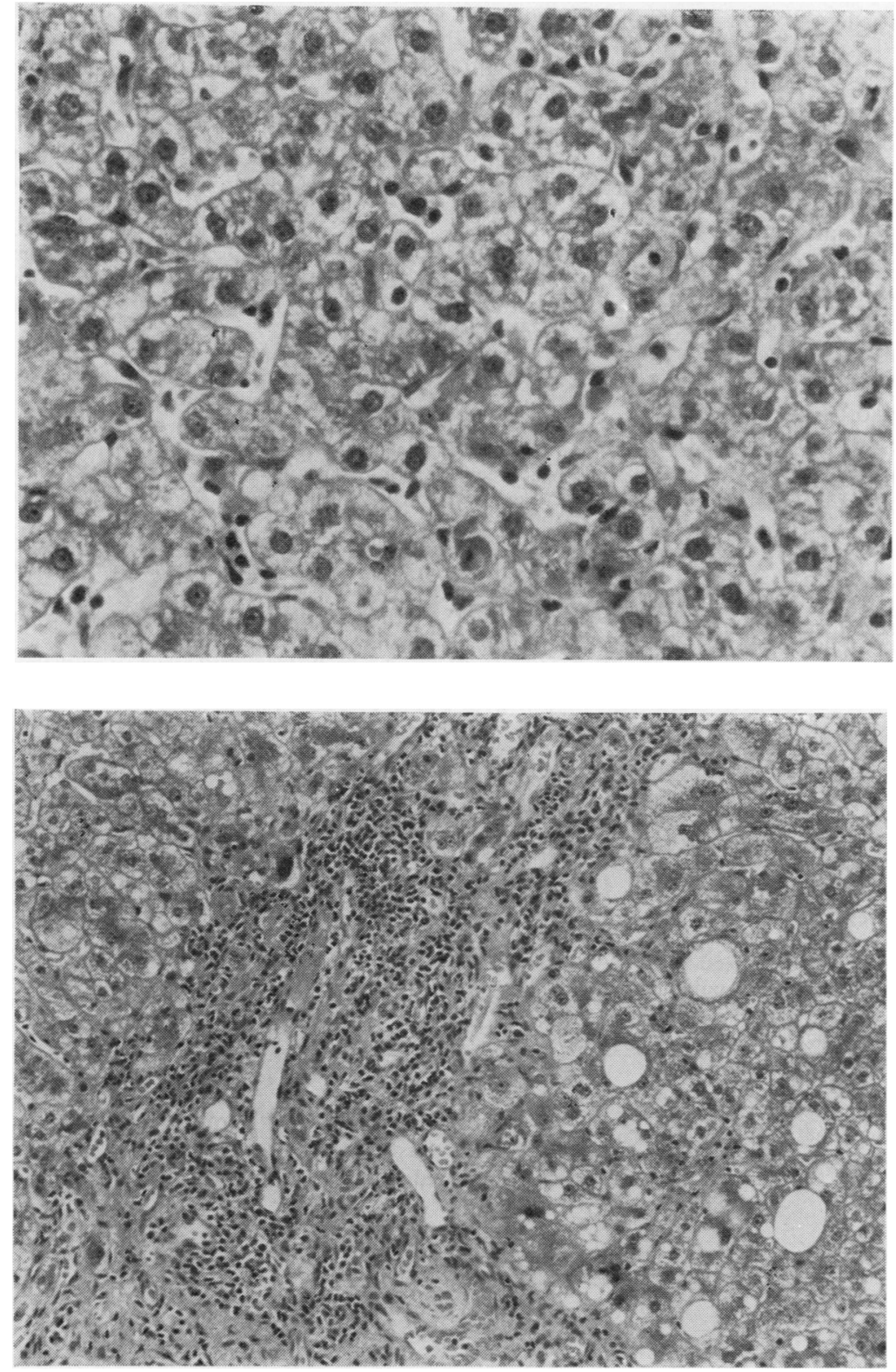

Fig. 3 Case 4: chronic persistent/chronic lobular hepatitis. Three portal tracts are infiltrated with mononuclear cells, also seen in the sinusoids. Haematoxylin and eosin $\times 145$.

Fig. 4 Case 4: higher magnification of part of biopsy shown on Fig. 2, showing lymphocytic infiltrate in sinusoids. Haematoxylin and $e o s i n \times 360$. hepatitis to a Liver Disease Unit. Our patients demonstrated normal immunoglobulin concentrations and none had SNF, SMA or AMA in greater concentrations than $1 / 10$. This picture contrasts with that of autoimmune hepatitis in which immunoglobulin concentrations are usually high and autoantibodies positive. Thus, these NANB patients are serologically distinct from autoimmune and more similar to $\mathrm{HBV}$-induced chronic liver disease.
Histological findings in liver biopsies covered the whole spectrum of acute and chronic hepatitis, and one patient had developed cirrhosis. While the histological features were basically those of acute and chronic hepatitis as described in published reports, the fatty change, excessive cellularity of sinusoids in relation to the degree of necrosis, and bile duct damage, were of interest. All three features have been found in short incubation NANB hepatitis in 
patients with coagulation disorders ${ }^{20}$ and it is possible that in our material the same virus was responsible for some of the lesions. Bile duct damage was, however, much less striking than in the coagulopathy group with the short incubation disease. The presence of considerable fatty change, particularly in the early weeks of acute hepatitis, was noteworthy because fatty change has been regarded as unusual in acute viral hepatitis and has been cited as one of the factors which should lead to a suspicion of possible drug aetiology. ${ }^{21}$ Its finding in the present series of biopsies indicates that it is a common feature also in NANB hepatitis. The excessive cellularity of the sinusoids seen in a few biopsies was similar to that noted in short incubation NANB hepatitis, ${ }^{20}$ and gave an appearance reminiscent of infectious mononucleosis or CMV hepatitis.

\section{References}

${ }^{1}$ Alter HJ, Purcell RH, Holland PV, Feinstone SM, Morrow AG. Clinical and serological analysis of transfusion-associated hepatitis. Lancet 1975; ii :838-41.

${ }^{2}$ Dienstag JL, Alaama A, Mosley JW, Redeker AG, Purcell RH. Etiology of sporadic hepatitis B surface antigennegative hepatitis. Ann Intern Med 1977;87:1-6.

${ }^{3}$ Mosley JW, Redeker AG, Feinstone SM, Purcell RH. Multiple hepatitis viruses in multiple attacks of acute viral hepatitis. $N$ Engl J Med 1977;296:75-8.

4 Wyke RJ, Tsiquaye KN, Thornton A, et al. Transmission of Non-A, Non-B hepatitis to chimpanzees by factor IX concentrates after fatal complications in patients with chronic liver disease. Lancet 1979; i :520-3.

"Tsiquaye KN, Zuckerman AJ. New Human hepatitis virus. Lancet $1979 ;$; $: 1135-6$.

${ }^{6}$ Vitvitski L, Trepo C, Prince AM, Brotman B. Detection of virus-associated antigen in serum and liver of patients with Non-A, Non-B hepatitis. Lancet 1979; : 1263-7.

${ }^{7}$ Shirachi R, Shiraishi H, Tateda A, Kikuchi K, Ishida N. Hepatitis ' $C$ ' antigen in Non-A, Non-B post transfusion hepatitis. Lancet 1978 ;ii:853-6.

${ }^{8}$ Villarejos VM, Visona KA, Eduarte CA, Provosti PJ, Hilleman MR. Evidence for viral hepatitis other than type A or type B among persons in Costa Rica. $N$ Engl J Med 1975;293:1350-2.
9 Hollinger FB, Alter HJ. Summary of workshop B6-NANB. In: Vyas GN, Cohen SN, Schmid R, eds. Viral hepatitis. Franklin Institute Press, 1978:697-702.

${ }^{10}$ Knodell RG, Conrad ME, Ishak KG. Development of chronic liver disease after acute Non-A, Non-B posttransfusion hepatitis. Gastroenterology 1977;72:902-9.

${ }^{11}$ Berman M, Alter MD, Ishak KG, Purcell RH, Jones EA. The chronic sequelae of Non-A, Non-B hepatitis. Ann Intern Med 1979;91:1-6.

12 Omata M, Afroudakis A, Liew C, Ashcavai M, Peters PL. Comparison of serum hepatitis $B$ surface antigen (HBsAg) and serum anticore with tissue $\mathrm{HBsAg}$ and hepatitis B core antigen ( $\mathrm{HBcAg}$ ). Gastroenterolog. 1978;75:1003-9.

${ }^{13}$ Mortimer PP, Vandervelde EM, Parry JV. Serological evidence for recent infection with hepatitis $A$ virus (HAV) following an institutional outbreak of hepatitis. $J$ Infect Dis 1979;1:269-75.

${ }^{14}$ Bianchi L, Zimmerli-Ning M, Gudat F. Viral hepatitis. In : MacSreen RNM, Anthony PP, Scheuer PJ, eds. Pathology of the liver. Edinburgh: Churchill Livingstone. 1979:164-91.

15 Bradley DW, Maynard JE. Serodiagnosis of viral hepatitis A by radioimmunoassay. Laboratory Management 1978; ii :29-34.

${ }^{16}$ Bianchi L, De Groote J, Desmet VJ, et al. Acute and chronic hepatitis revisited. Lancet 1977;ii:914-9.

17 Poulsen H, Christoffersen P. Abnormal bile duct epitheliun? in liver biopsies with histological signs of viral hepatitis. Acta Pathol Microbiol Scand 1969;76:383-90.

${ }^{18}$ Mathieson LR, Skinoj P, Nielsen JD, Purcell RH, Wong D, Ranek L. Hepatitis type A, B and Non-A in fulminant hepatitis. Gut 1980;21:72-7.

${ }^{19}$ Rakela J, Redeker A. Chronic liver disease after acut: Non-A, Non-B viral hepatitis. Gastroenterology 1979 77:1200-2.

${ }^{20}$ Bamber M, Murray AK, Thomas HC, et al. Short incu? bation Non-A, Non-B hepatitis transmitted by factor VIII concentrated in patients with haemostatic disorders. Gut (in press).

${ }^{21}$ Bianchi L, De Groote J, Desmet V, et al. Guidelines for diagnosis of therapeutic drug-induced liver injury in liver biopsies. Lancet 1974 ; i:854-7.

Requests for reprints to: Dr M Bamber, Department of Medicine and Histopathology, Royal Free Hospital, Hampstead, London NW3 2QG, England. 